\title{
Practical management of perinatal death
}

\author{
GILLIAN C FORREST, R S CLARIDGE, J D BAUM
}

\section{Summary and conclusions}

After the loss of a newborn baby the parents are usually too shocked and unfamiliar with the complicated administration procedures to cope with the registration of death and burial (or cremation). The medical and nursing staff also tend to be unfamiliar with the procedures. Some of these can be streamlined, thus reducing the stress caused to parents. By giving positive instruction and more information the staff will in their turn be able to improve their care of the bereaved parents.

\section{Introduction}

The loss of a newborn baby is tragic for both the parents and the medical and nursing staff. Its effects are probably even greater now that expectations of the safe delivery of a healthy baby are so high. When things do go wrong the parents are shocked: they are often emotionally too inexperienced to deal with bereavement; furthermore, they are usually unfamiliar with the complicated administration procedures necessary to register and bury (or cremate) a dead person. The medical and nursing staff also tend to be unfamiliar with these procedures and unable to help parents. We describe these procedures and suggest several practical ways of helping bereaved parents.

\section{Registration of neonatal death and stillbirth}

The law requires that the death or stillbirth of all babies is registered at the local office of the Registrar of Births, Marriages, and Deaths. ${ }^{1}$

Park Hospital for Children, Oxford

GILLIAN C FORREST, MRCGP, MRCPSYCH, senior registrar in child psychiatry

John Radcliffe Hospital, Oxford

R S CLARIDGE, social worker

J D BAUM, MD, FRCP, clinical reader, university department of paediatrics
All liveborn babies and those stillborn after 28 weeks' gestation require proper burial or cremation. For babies stillborn before 28 weeks' gestation, the parents may, if they wish, hold a funeral, but this is not a legal requirement.

\section{NEONATAL DEATH}

These babies will already have had a birth certificate issued, and the parents may have had time to register the birth. After the baby dies the doctor concerned issues a medical certificate of cause of death, which has to be taken within five days to the registrar's office nearest to the hospital where the baby died. If the parents have not had time to register the baby's birth they will have to register simultaneously the birth and death.

The registrar then issues the parents with the certificate of burial or cremation that is required by the undertaker before any funeral arrangements can be made. The parents will also be given an application form for the death grant ( $£ 9$ for babies) provided by the Department of Health and Social Security to "offset" the funeral expenses.

\section{STILLBIRTH}

No birth certificate is issued for a stillborn baby. The doctor issues a medical certificate of stillbirth which must be taken to the registrar's office within six weeks. A certificate of burial or cremation will then be issued to the parents, as for a neonatal death. The parents of a stillborn baby are not eligible for a death grant. Instead, the hospital administrators are directed by DHSS to meet the costs of any stillborn baby's funeral, unless the parents specifically indicate that they want to pay for this themselves. ${ }^{3}$

\section{Funeral arrangements}

It is possible for parents to choose either a funeral arranged by the hospital or a private one to be arranged by themselves with any firm of undertakers. 
HOSPITAL FUNERAL

The hospital funeral is carried out by an undertaker contracted to the hospital and has the advantage of relieving parents of the burden of making these arrangements. There are, however, many myths and misconceptions about hospital funerals, among staff as well as parents: babies may be collected up and placed in a mass grave, without coffins or any ceremony; they may be placed together with an adult corpse in an adult's coffin; they may remain unburied for many weeks; the site of the burial is secret and parents cannot attend the funeral or visit later.

In fact the hospital funeral should provide a plain white coffin, proper transport to a local cemetery, and burial in a grave that is usually in a part of the cemetery set aside for babies. The grave itself will usually have a total capacity of several babies, over the years. A clergyman is provided in the case of a neonatal death (but not a stillbirth). The burial should be carried out within a few days and parents permitted to attend, if they wish. They should also be informed of the site of the grave later by the hospital administrators if they do not attend. The cost of a hospital burial of a baby dying in the neonatal period is currently about $£ 40$. The hospital can also arrange a cremation, and this will cost the parents about $£ 100$ (Oxford prices).

Parents commonly encounter several difficulties if they do choose a hospital funeral. They are often not informed by the undertaker or the hospital of the date and time of the baby's funeral, and they will have to tell the hospital administrator if they would like to attend. If they do not attend the funeral they often have difficulty finding the site of the grave later, as they will usually be sent a plot number only and most cemeteries do not have an attendant present all the time to show parents the plots. It is often possible to help parents over this difficulty by advising them to contact the cemetery office at the town hall or local district council offices before attempting to visit the cemetery. The cemetery clerk may be helpful in showing parents the cemetery plan or arranging for the grave to be temporarily marked for them.

Another problem arises when parents want to mark their baby's grave later. In some areas this is not possible if the baby has been buried in a multi-occupancy grave. If the parents, however, purchase an exclusive grave (before the baby is buried) for an additional fee of about $£ 25$, then they may erect a headstone.

\section{PRIVATE FUNERAL}

For a private funeral the parents will arrange with a private undertaker whatever they require for the burial or cremation of their baby. The cost varies enormously and can be anything from $£ 30$ to $£ 150$ (Oxford prices).

\section{CERTIFICATE OF BURIAL OR CREMATION}

The parents have to deliver a certificate of burial or cremation either to the hospital administrator for a hospital funeral or to the undertaker for a private funeral. The collection and delivery of the various certificates is bewildering and exhausting for parents (usually the father). Practice varies from hospital to hospital but in Oxford we have found that the parents can be saved an unnecessary journey if their requirements for the funeral are discussed with them by the ward staff when they collect the certificate of stillbirth or cause of death (figs 1 and 2). Those parents who want a private funeral need not return to the hospital administrator with the certificate of burial or cremation. It is also possible to relieve very distressed parents of the burden of registration by arranging for a member of the hospital staff to do this for them.

\section{BEREAVEMENT COUNSELLING}

As Parkes concludes in his recent review, ${ }^{4}$ there is now evidence that bereavement counselling can reduce the risk of the psychiatric and psychosomatic disorders that result from bereavement. Many newly-bereaved parents, however, find it difficult to accept offers of counselling and emotional support. We have found that offering help initially with the practical issues of registration and funeral arrangements facilitates the parents' acceptance of more general emotional support and bereavement counselling. It seems, therefore, that

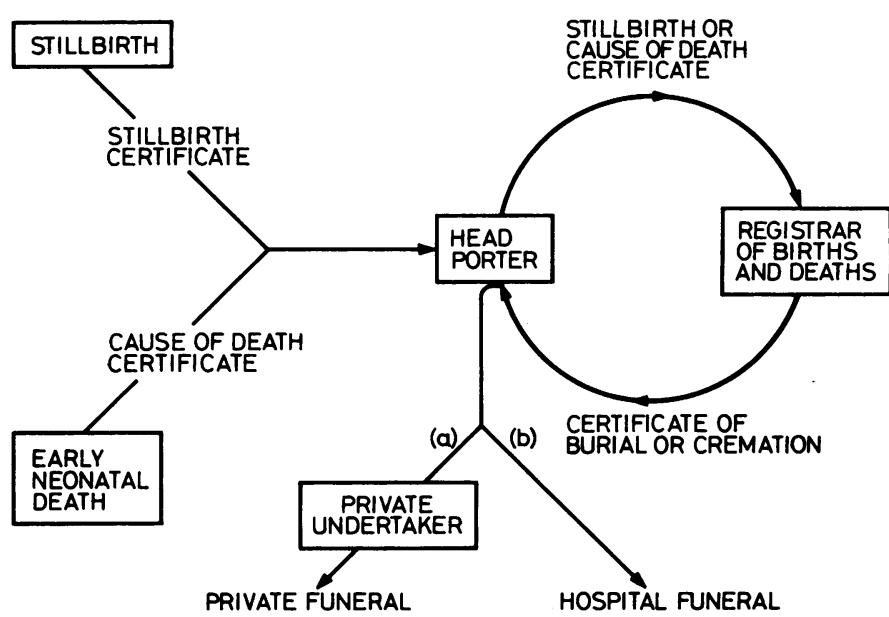

FIG 1-Complicated procedure for registering death or stillbirth and arranging funeral.

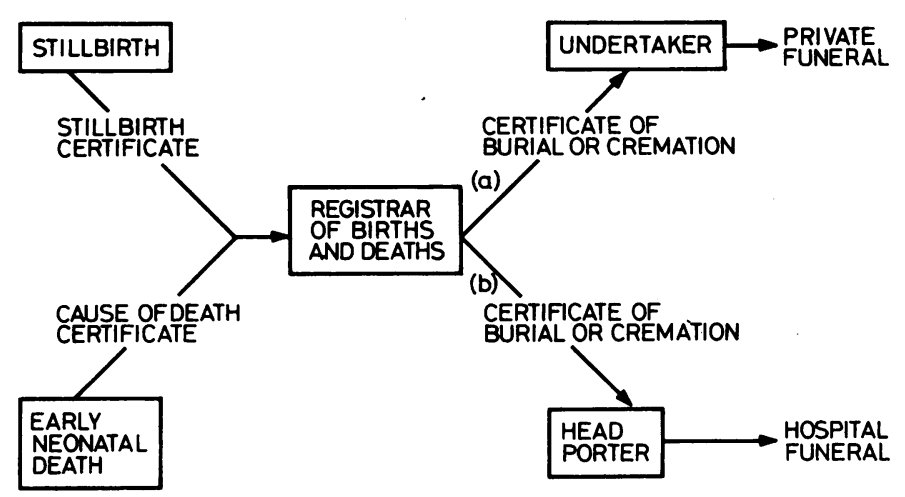

FIG 2-Simplified procedure for registering death or stillbirth and arranging funeral.

familiarity with whatever arrangements exist locally is important for anyone engaged in counselling newly bereaved parents.

\section{Conclusions}

Some of the procedures necessary in registering the death and funeral arrangements for babies who die in hospital can be streamlined, thus reducing the stress they cause to parents who have lost a baby in the perinatal period. By giving positive instruction and more information about these procedures to medical and nursing staff, they will in their turn be able to improve their care of bereaved parents. Familiarity with these practical issues facilitates an entrée to bereavement counselling for the parents.

We thank Mrs Ashfield, bereaved persons welfare officer, John Radcliffe Hospital, Oxford; $\mathrm{Mr}$ Duckworth, undertaker; and $\mathrm{Mr}$ Lockwood, cemetery clerk, Oxford Town Hall, for their invaluable help in preparing this paper, and all those parents who have shared with us their experiences of losing their baby.

\section{References}

1 Births and Deaths Registration Act 1953. London: HMSO.

2 Department of Health and Social Security. Death grant. London: DHSS, 1979. (DHSS leaflet NI 49.)

3 Department of Health and Social Security. Funerals for stillborn babies. London: DHSS, 1975. (DHSS circulars DS 211/75 and HN(76)18.)

4 Parkes CM. Bereavement counselling: does it work? $\mathrm{Br} M e d \mathcal{F}_{1980}$; 281 :3-6.

(Accepted 17 October 1980) 